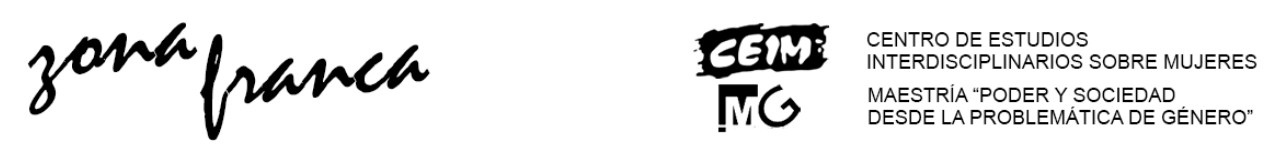

\title{
De Lilits, Evas y Adanes: Género y Ciencias Sociales o de incomodidades, certezas y apuestas
}

Adriana Valobra ${ }^{*}$

\section{Resumen}

En este artículo, reflexionamos sobre los caminos de las mujeres en el campo científico académico, una meditación sobre nuestros lugares en él. Si este ejercicio no es nuevo, sigue siendo necesario. En este sentido, sistematizo una serie de incomodidades, ciertas certezas y un conjunto de apuestas que apoyan mi trabajo académico y político. Organizaré mi artículo en seis secciones. Las cuatro primeras dimensiones, las que propuso la historiadora feminista Joan Scott (Scott, 1996), con respecto al concepto de género. En este sentido, reflexionamos sobre lo simbólico, lo normativo, lo institucional y lo subjetivo en la construcción de sentidos de género en el sistema científico. Finalmente, dos apartados más, uno que intenta volver a enhebrar las problemáticas de la epistemología y la pedagogía y, finalmente, otro sobre la necesaria intervención política que nos reclaman estas cuestiones de inequidad en materia de género.

Palabras claves: Género- Epistemología- Ciencia- Argentina

\section{About Lilits, Evas y Adanes: Gender and Social Sciences or about discomforts, certainty and gambles}

\section{Abstract}

In this article, We reflects on the paths of women in the academic scientific field, a meditation on our places in it. If this exercise is not new, it is still necessary. In this sense, I systematize a series of discomforts, certain certainties and a set of

* Centro Interdisciplinario de Investigaciones en Género- Instituto de Investigaciones en Humanidades y Ciencias Sociales- Consejo Nacional de Investigaciones Científicas y Técnicas Universidad Nacional de La Plata. Contacto: profeindiva@gmail.com

Valobra, Adriana. "De Lilits, Evas y Adanes: Género y Ciencias Sociales o de incomodidades, certezas y apuestas" en Zona Franca. Revista del Centro de estudios Interdisciplinario sobre las Mujeres, y de la Maestría poder y sociedad desde la problemática de Género, №27, 2019 pp.123154. ISSN, 2545-6504 Recibido: 07 de mayo 2019; Aceptado: 13 de diciembre 2019

Revista Zona Franca- Centro de estudios interdisciplinario sobre las mujeres (CEIM)- Maestría poder y sociedad desde la problemática de género (MG), Rosario, Argentina. ISSN, 2545-6504 http://zonafranca.unr.edu.ar/index.php/ZonaFranca| Numero 27 (2019). 
bets that support my academic and political work. I will organize my article in six sections. The first four dimensions, those proposed by feminist historian Joan Scott (Scott, 1996), regarding the concept of gender. In this sense, we reflect on the symbolic, the normative, the institutional and the subjective in the construction of gender senses in the scientific system. There are two more sections, one that tries to rethink the problems of epistemology and pedagogy and, finally, another section about the necessary political intervention that gender inequality issues demand.

\section{Keywords: Gender- Epistemology-Science- Argentina}

La comparación a la que aludo en el título de este trabajo trae a la escena dos figuras femeninas bíblicas y la del primer "hijo del Padre". La idea, tal vez contradictoria para comenzar una reflexión sobre la ciencia, me resulta útil puesto que nos coloca frente al problema del género que subyace en el sistema científico. Lilit, aparentemente, sería la primera mujer creada por dios a su imagen y semejanza al igual que Adán. Sin embargo, rápidamente, el anecdotario de las tradiciones judeo-cristianas nos deja entrever que Adán intentó posicionarse jerárquicamente sobre Lilit y que quiso imponerse colocándola debajo de sí en las relaciones sexuales. Lilit, consciente de su condición igualitaria respecto de Adán, lo rechazó, se fue del Edén y entró en vínculo con lo demoníaco, entregándose a los placeres sensuales de la carne a su gusto y posición. Tras rechazar a tres ángeles enviados para convencerla de volver a tomar la senda de Dios, fue castigada a que sus hijos e hijas murieran a centenares y, en represalia, ella robó seres neonatos engendrados por quienes la condenaban. Eva, en cambio, fue creada por Dios de una costilla de Adán con la esperanza de que se acomodara a los imperativos de éste. Sin embargo, mientras la versión que habla sobre Lilit coloca el tema sexual en el centro de la confrontación; en este caso, la relación de Adán y Eva no tenía -supuestamente- estos fines. Sin embargo, Eva rompió el pacto de la ignorancia complaciente con Dios y al morder del árbol del fruto prohibido y darle a probar a Adán, desató las sensualidades de las que los habían inhibido, por lo que sufrirá no sólo el castigo de parir con dolor sino, antes, el de embarazarse y convertirse en objeto de los placeres de otro, pero no de los propios. En todo caso, las Lilits y las Evas se parecen en tanto su cuerpo es el

Revista Zona Franca- Centro de estudios interdisciplinario sobre las mujeres (CEIM)- Maestría poder y sociedad desde la problemática de género (MG), Rosario, Argentina. ISSN, 2545-6504 http://zonafranca.unr.edu.ar/index.php/ZonaFranca| Numero 27 (2019). 
primer lugar de conocimiento prohibido, sus sentidos son una manera de conocer y conocerse y su curiosidad y su convicción sobre lo que quieren las lleva a un camino de conocimiento. Adán, claro representa a nuestros colegas varones en el ámbito científico que asumen alternativamente la posición despótica de Adán para con Lilit o la ingenua y desentendida de sus responsabilidades frente a los hechos. Dios, qué duda cabe, es la Ciencia, con mayúsculas, que nos dice que somos iguales como sujetos que conocen, pero brinda a los Adanes las condiciones de posibilidad para que las mujeres, como Lilit, dejemos el Edén, el sistema científico, o nos quedemos en él, como Eva, culposas y sufrientes. Lilit y Eva, finalmente, a pesar de tener en común la búsqueda del conocimiento; se contraponen. Eva es obligada a gestar y parir al infinito y Lilit, roba su descendencia. $Y$ si estas imágenes pueden resultar chocantes para pensar el sistema científico, no resultan tan altisonantes cuando hacemos el ejercicio de preguntar sobre las relaciones de género en la ciencia y constatar que esas modelizaciones persisten.

Esta comparación me permite intentar una reflexión sobre las derivas de los recorridos de las mujeres en el ámbito científico académico, una reflexión sobre nuestros lugares en él que, si bien no es nueva', sigue siendo necesaria".

Y una vez más emprendo la escritura para ordenar ideas porque de nuevo sigue siendo necesario y porque "escribir es comprometerse desde el deseo en la escritura de cuerpos (...) pero mientras tanto vamos dejando el nuestro (...) en el camino" (Ztardust 2013, p. 13). En ese sentido, me propongo sistematizar una serie de incomodidades, algunas certezas y un conjunto de apuestas que sostienen mi trabajo académico y político mientras que no deja de ser una "interruqción" en el sentido que Val Flores le da a la palabra en relación con la

\footnotetext{
' Es difícil remitir a todos los aportes precedentes, algunos de los cuales se mencionarán aquí. Para un estudio reciente sobre la epistemología feminista: (Campagnoli 2018).

"Este trabajo se basa en la conferencia a la que fui invitada para abrir el VI Workshop "Distintas experiencias de abordaje de la perspectiva de género en la UNRosario". Facultad de Ciencia Política y Relaciones Internacionales. Universidad Nacional de Rosario, el 24 de octubre de 2017. Quiero a agradecer a la Dra. Maricel Bertolo esta invitación a pensar el cruce entre género y ciencias sociales a partir de mi experiencia de investigación en CONICET.
}

Revista Zona Franca- Centro de estudios interdisciplinario sobre las mujeres (CEIM)- Maestría poder y sociedad desde la problemática de género (MG), Rosario, Argentina. ISSN, 2545-6504 http://zonafranca.unr.edu.ar/index.php/ZonaFranca| Numero 27 (2019). 
práctica educativa de "interferir los guiones hegemónicos del género binario, del régimen político de la heterosexualidad, de la blanquedad autoinvisibilizada, de los procesos de normalización de los sujetos (...) suspender algunas lógicas prescriptivas que se instalan silenciosa y poderosamente en los formatos educativos" (flores 2013, p. 19) y científicos, agregaría. Y aunque esta reflexión está lejos de la poética que propugna flores, se nutre en la idea de "hacer del pensamiento una provocación permanente, inmiscuirse en las turbulencias de lo que (me) está pasando, abandonarse al tránsito de la vida practicando una política del detalle" (flores 2013, p. 21).

Organizaré mi intervención en seis apartados. Los cuatro primeros serán instrumentados a partir de considerar las dimensiones propuestas por la historiadora feminista Joan Scott (Scott, 1996) respecto de la concepción de género. En ese sentido, propongo reflexionar sobre lo simbólico, lo normativo, lo institucional y lo subjetivo. Finalmente, dos apartados más, uno que intenta volver a enhebrar las problemáticas de la epistemología y la pedagogía feministas y, finalmente, otro sobre la necesaria intervención política que nos reclaman estas cuestiones de inequidad en materia de género.

\section{Un universo simbólicamente contradictorio de contundencia brutal}

Respecto de lo simbólico, resulta útil traer a cuento que no por representacional es menos material. Ya nos advierte oportunamente de esto Pierre Bourdieu quien, aunque realiza una increíble operación de supresión simbólica a la referencia de un reguero de producciones feministas que abordaron el tema, subraya que

\footnotetext{
"El trabajo de construcción simbólico no se reduce a una operación estrictamente performativa de motivación que orienta y estructura las representaciones, comenzando por las representaciones del cuerpo (lo que no es poca cosa); se completa y se realiza en una transformación profunda y duradera de los cuerpos (y de los cerebros), o sea, en y a
}

Revista Zona Franca- Centro de estudios interdisciplinario sobre las mujeres (CEIM)- Maestría poder y sociedad desde la problemática de género (MG), Rosario, Argentina. ISSN, 2545-6504 http://zonafranca.unr.edu.ar/index.php/ZonaFrancal Numero 27 (2019). 
través de un trabajo de construcción práctico que impone una definición diferenciada de los usos legítimos del cuerpo, sexuales sobre todo, que tiende a excluir del universo de lo sensible y de lo factible todo lo que marca la pertenencia al otro sexo - (...) - para producir ese artefacto social llamado un hombre viril o una mujer femenina" (Bourdieu 2000; $p$. 37).

Así, el universo representacional que se asocia a las nociones de género y ciencias sociales diferencia entre lo femenino y la ciencia, lo masculino y la ciencia. $Y$ aunque entiendo que hablo como mujer y me posiciono como tal -con lo inestable que puede ser esa definición y renegando de sus halos semánticos patriarcales así como del biologicismo reductivo-, uso adrede la noción de femenino para no anclar sólo en la reflexión sobre lo que entendemos como mujer o mujeres (Maffía 2003; Wayar 2018); sino para pensar que en una femineidad, cualquiera sea su expresión, se visualiza una contradicción, una incompatibilidad con la definición de ciencia; incompatibilidad fundada por esa misma ciencia y sus parámetros de cientificidad históricamente construidos. En efecto, en uno de los aportes fundamentales de la discusión entre feminismo y ciencia, la física norteamericana Evelyn Fox Keller da una clave sobre la relación ciencia y género cuando se pregunta "en qué medida está ligada la ciencia a la idea de masculinidad" y "qué pasaría si la ciencia fuera distinta" (Fox Keller 1991; p. 28). La autora plantea que un estudio sobre la relación entre género y ciencia no está implicando sólo a las mujeres, sino que involucra a los varones y, más precisamente, a la feminidad y masculinidad, donde con ambos términos se "asume que la propia conducta es resultado del tipo de persona que se es. Es decir, una persona no-masculina se comportaría diferente" (Connell 1997, p. 79). Según Fox Keller (1991), género y ciencia son categorías construidas socialmente, creadas por fuerzas cognitivas, emocionales y sociales que se dan en relaciones sociales complejas lo cual nos obliga a revisar la conjunción histórica entre ciencia y masculinidad, a la vez que la disyunción, también histórica, entre ciencia y feminidad y elaborar estrategias para su modificación.

Revista Zona Franca- Centro de estudios interdisciplinario sobre las mujeres (CEIM)- Maestría poder y sociedad desde la problemática de género (MG), Rosario, Argentina. ISSN, 2545-6504 http://zonafranca.unr.edu.ar/index.php/ZonaFrancal Numero 27 (2019). 
En este punto, voy a volver sobre mis pasos para reflexionar sobre las implicancias de ser vista como mujer en el ámbito científico porque, en particular, advierto que las representaciones que se tejen en ese ámbito, contradictorias muchas veces, se vinculan a la mirada persistentemente biologicista que reproduce el modelo de científico, lo que lleva a Sandra Harding a preguntarse si la categoría "mujer científica" no es de por sí una contradicción. Para la definición hegemónica de ciencia, la respuesta es categóricamente que sí, y esa contradicción de los propios términos "pone de manifiesto las diferencias entre la retórica <progresista> del cientificismo, las prácticas concretas de los científicos individuales y de la ciencia como institución y los significados simbólicos de la masculinidad, la feminidad y la ciencia. El contexto social y político más general en el que se produce la discriminación contra las mujeres en la ciencia forma parte de las relaciones sociales generizadas, en general, así como del panorama psíquico en cuyo marco se desarrolla el pensa miento de los científicos masculinos individuales sobre sí mismos y sobre la natu raleza de la ciencia" (Harding 1996, p. 53). La ciencia, por otra parte, una y otra vez reedita impertérrita esas cosmovisiones, y aunque ha sido criticada con éxito, incluso, desde las propias ciencias biológicas (Lewontin, Rose y Kamin, 1987), tal el caso de las neurociencias que abonan el terrenos de los pares duales (Ciccia 2018).

Según la abogada Frances Olsen (Olsen 1990), en términos conceptuales, esa exclusión de las mujeres del ámbito de lo racional -que aún persiste- tiene que ver con el modo en que se estructuró el pensamiento liberal clásico, desarrollado en torno a esquemas duales, binarios, o pares opuestos que afilian lo masculino, con lo racional, lo activo, el pensamiento, lo cultural, el poder, la objetividad, lo abstracto y la universalidad; mientras que adjudican a lo femenino los opuestos complementarios a aquellas categorías: irracional, pasivo, sentimental, ligado a la naturaleza, sensible, subjetivo, concreto y particular. Agrego que, esas características, además, cuentan con un espacio social segregado que define como propio de lo masculino el orden público (el mercado,

Revista Zona Franca- Centro de estudios interdisciplinario sobre las mujeres (CEIM)- Maestría poder y sociedad desde la problemática de género (MG), Rosario, Argentina. ISSN, 2545-6504 http://zonafranca.unr.edu.ar/index.php/ZonaFranca| Numero 27 (2019). 
la política) y el privado, reservado a lo femenino. La ciencia, por su asociación con lo masculino, se encuentra en el ámbito público (con algunas singularidades que luego señalaremos) porque es en el ámbito público donde se valida y se reconoce su aporte"I'. El Edén del sistema científico, por volver a la figura con la que comenzamos, tiene quien lo transite con legitimidad y Lilit y Eva no son legítimas cientistas lo que las hace perderse en los laberintos de la ciencia. Lilit es expulsada de él y Eva, con suerte, puede cumplir funciones de asistencia entendidas como de menor rango. Para Olsen, todo el campo del conocimiento y dominio de saber ha estado sustentado en tres pilares: sexualización, jerarquización y prescripción solapada. El primer pilar se consolida con la sexualización dualista del pensamiento que conduce a la reducción de los fenómenos en términos binarios de masculino y femenino. A continuación, el siguiente pilar, es mediante el cual se infringe una relación jerárquica a esos pares duales según la cual lo masculino y todo lo que se le asocia se entiende como superior y valorativamente, mejor; mientras que lo femenino, es su contrario y complemento, lo inferior y negativo. Los lazos de arraigo con el espacio considerado privado o doméstico y el espacio de la naturaleza se anclan a lo femenino y todo lo contrario, vale decir, a lo insensible, desapegado, racional que se despliega sobre los escenarios de lo público, concretamente, lo político, lo laboral y lo científico, se vincula a lo masculino. Finalmente, el tercer aspecto es que estas características, se presentan como si fueran descripciones aunque, más

III Quisiera mencionar, a modo de reflexión sobre las observaciones formuladas por uno de los referatos a quien agradezco la oportunidad de explayarme, que aquí la cuestión está pensada en relación no tanto con los capitales que sustentan una investigación -públicos o privados-; sino en sintonía con la necesaria reafirmación de la ciencia en el espacio público que es, además, un espacio de validación en tanto, también, resulta ser el lugar de la publicidad de la misma. En el sentido de la crítica de Nancy Fraser a la idea habermasiana de espacio público dialógico plural, supone reconocerlo, también, en las fragmentaciones e inequidades que construye y potencia así como en la necesaria delimitación de los intereses privados que juegan en él. Esto mismo, no inhibe, tampoco, la idea de que el conocimiento se valida en el espacio público y, efectivamente, tampoco ignora que las formas de comunicación de la ciencia tienen circuitos especializados dedicados a públicos restringidos y que las vías de la divulgación científica pueden suponer canales poco fluidos para quienes no son especialistas. Como señala Fraser (1993, 31), "la mujer estaba excluida del ámbito público resulta ser ideológica; se basa en una noción de lo público con prejuicios de clase y de género", en analogía con ello es que se piensa la exclusión de la mujer de la ciencia y la incorporación de la ciencia como un dominio público asociado a la masculinidad.

Revista Zona Franca- Centro de estudios interdisciplinario sobre las mujeres (CEIM)- Maestría poder y sociedad desde la problemática de género (MG), Rosario, Argentina. ISSN, 2545-6504 http://zonafranca.unr.edu.ar/index.php/ZonaFrancal Numero 27 (2019).

Página 129 
bien, son prescripciones que proponen/imponen la vinculación masculino-ciencia y asociaciones con la objetividad, sistematicidad, control, organización (Olsen 1990).

La filósofa argentina Diana Maffía, empapada de los aportes de Olsen, expone con precisión cómo operan esos mecanismos:

"Entonces si tenemos un estereotipo de lo que es un varón y un estereotipo de lo que es una mujer y además jerarquizamos esas categorías, estamos jerarquizando reforzadamente a las mujeres con respecto a los varones en una inferioridad. Se dice, por ejemplo, <es extremadamente emocional para asumir un cargo público>, <es demasiado emotiva para ocupar una función de tanta responsabilidad>. Argumentos de este tipo no dicen <no, porque es una mujer>. El estereotipo sirve para ocultar el sexismo: dicen <no> porque tiene un rasgo (emocionalidad, particularidad, subjetividad) que es inferior. Un rasgo que se define como femenino y que culturalmente consideramos como un rasgo disvalioso. Entonces los argumentos con los cuales se descalifica a la mujer, ya no necesitan decir <no, porque es una mujer>, tienen una línea larguísima de conceptos con los cuales se puede descalificar, contando con la aceptación incluso de nosotras mismas, las mujeres -porque la ideología no está en las hormonas sino en las ideasde que unos elementos son más valiosos que los otros" (Maffía n.d.-b).

Esas características de la ciencia excluyen por definición a las mujeres que son naturalmente disruptivas del orden social como ha demostrado la politóloga Carole Pateman respecto de las visiones sobre las mujeres en el pacto social, fundamento de la democracia moderna, violenta y excluyente (Pateman 1995).

Ahora bien, estas representaciones simbólicas se anudan en cierto modo con algo que tiene que ver también con la concepción del científico como una persona ajena al trajín de la vida cotidiana porque, de alguna manera, su racionalidad le permite abstraerse de ella y, al mismo tiempo, se lo exige. Esta característica lleva a que se desidentifique de su rol como trabajadora o trabajador, de quienes trabajan con el intelecto si se quiere, pero trabajadora y trabajador al fin. Esto se explica, en parte, porque el origen social de la mayoría de las personas que se

Revista Zona Franca- Centro de estudios interdisciplinario sobre las mujeres (CEIM)- Maestría poder y sociedad desde la problemática de género (MG), Rosario, Argentina. ISSN, 2545-6504 http://zonafranca.unr.edu.ar/index.php/ZonaFranca| Numero 27 (2019). 
dedican a la investigación proviene de sectores medios y altos y difícilmente somos mayoritarias personas que tenemos un origen social objetivamente proletario. Vale decir, sería muy difícil encontrar a alguien investigando en CONICET que haya vivido en una villa o en un conventillo sin estar haciendo allí trabajo de campo. Pero si lo logra, la marca de su origen no dejará de señalar lo volátil de su posición; de astillar su proyección. Es que la clase también hace su preselección y, en ese juego, el caso excepcional es el que construye la regla (Pérez 2008). Si a esas desidentificaciones le agregamos otras que promueve el ideal del intelectual, encontramos por caso, los saberes indígenas cercenados como reflexiones que pueden aportar al conocimiento y ofrecer una perspectiva epistemológica relevante (Bach 2018). Es lo que Jules Falquet la combinatoria straight, como

"el conjunto de estas instituciones y reglas que organizan solidariamente la alianza y la filiación en función de lógicas simultáneas de sexo, «raza» y clase. (...) [que] crea continuamente grupos humanos considerados como diferentes, cuyas incompatibilidades o relaciones privilegiadas son luego presentadas como estrictamente naturales (o como la mismísima base de la cultura). Por esta razón, la combinatoria straight es el operador central de la dinámica simultánea de las relaciones estructurales de sexo, de raza y de clase" (Falquet 2017, s/p).

$\mathrm{Y}$ hay muchas otras omisiones, incluso, corporales inaceptables para los stándares sobre qué es un científico (en masculino). La biologización sexualizada de los cuerpos, en efecto, no se aparta de la norma binaria que, además, impregna de una cierta sexualidad esos cuerpos y adscribe ciertas funciones, incluso cerebrales, de manera dual. Con esa operatoria, excluye la heterogénea realidad corporal, sexuada y racional y sólo considera incorporar ciertos cuerpos, sexualidad y racionalidades que se acercan a los ideales pergeñados. La sensualidad asociada a lo femenino -en términos culturales y no biologicistas-es expulsada del universo científico como si no fuera parte de lo masculino, que hegemoniza lo racional. También, en esa lógica, la exclusión de las

Revista Zona Franca- Centro de estudios interdisciplinario sobre las mujeres (CEIM)- Maestría poder y sociedad desde la problemática de género (MG), Rosario, Argentina. ISSN, 2545-6504 http://zonafranca.unr.edu.ar/index.php/ZonaFranca| Numero 27 (2019). 
masculinidades lésbicas, por ejemplo, sería otra forma de preservar una cierta masculinidad cis ajustada a los cánones de ciencia modélica.

Las representaciones sobre las mujeres las colocan en el mundo de lo cotidiano $\mathrm{y}$, aunque no hace un reconocimiento de lo que se llama trabajo reproductivo (y no remunerado) en la división sexual del trabajo; en realidad, se la asocia a ese universo interminable de quehaceres que, en el fragor de los días, apenas le dejarían tiempo para ver la telenovela mientras plancha (y claro que estoy siendo irónica con esto). Esas visiones, lógicamente, la descalifican como cientista (tanto como intelectual como académica, aunque no son estrictamente lo mismo). Tal vez, aquí esté la razón por la que es tan difícil para el universo de personas dedicadas a la investigación en CONICET -por ejemplo-reclamar paritarias con sentido y no las migajas que el gremio del personal civil de la nación está "negociando" sin conflicto, exigir que el descuento de ganancias deje de operar pues no somos una empresa o que dejen de descontarse esos ingresos brutos de manera irregular al punto de que en algunos meses no encuentres en tu cuenta más que dos tercios del salario, tampoco es fácil realizar un paro o una toma del lugar de trabajo como medida de fuerza gremial: todo ello sería como reconocerse personas que trabajan. Es que el sujeto colectivo del cientista incluso social—, se atomiza, se vuelve individual y no social.

En este proceso de invisibilización del quehacer científico, las mujeres científicas cargamos además con la connotación cultural según la cual ni somos científicas ni trabajamos -al menos, según los estereotipos y bastimentos de orden simbólico- por lo tanto, somos expresión de la negación de nuestra presencia y de los resultados de nuestra intervención ${ }^{\mathrm{IV}}$. $\mathrm{Y}$ voy a subrayar que esta

IV Esa operación, como ha señalado Rich retomando a Kathleen Gough, supone ocho características del poder masculino en sociedades arcaicas y contemporáneas: "la capacidad de los hombres de negarles a las mujeres una sexualidad o de imponerla sobre ellas; de forzar o explotar su trabajo para controlar su producto; de controlar o usurparles sus criaturas; de confinarlas fisicamente e impedirles el movimiento; de usarlas como objetos en transacciones entre

Revista Zona Franca- Centro de estudios interdisciplinario sobre las mujeres (CEIM)- Maestría poder y sociedad desde la problemática de género (MG), Rosario, Argentina. ISSN, 2545-6504 http://zonafranca.unr.edu.ar/index.php/ZonaFrancal Numero 27 (2019). 
doble carga está enlazada con una tercera. Si hasta ahora me referí a temas vinculados a las ciencias en general, adentrarnos en las aguas de las ciencias sociales (¿y humanas?) esta doble carga referida a la mujer científica, se enlaza con una tercera subalternización impuesta por el orden jerárquico que atraviesa a las ciencias que enaltece a las ciencias a secas respecto de las otras ciencias, menores, cuyo estatuto de ciencia es siempre cuestionable. Esas ciencias a secas, auto-denominadas exactas y naturales, reponen un problema ontológico y epistemológico al no reconocer el maderamen social e imaginario sobre el que se montan sus propias disciplinas y, el papel de las subjetividades que atraviesan ese campo disciplinar. Tal vez por ello, algunos de los aportes más sugestivos a la hora de apuntar las tensiones entre género y ciencia provengan de cientistas de la ciencia a secas como son Evelyn Fox Keller, Sandra Harding y Donna Haraway que han puesto en primer lugar la relación entre quiénes producen ciencia y los resultados de la ciencia que producen; es decir, abordan el conocimiento producido partiendo desde la singularidad del sujeto cognoscente.

La persistencia de esas nociones en las ciencias sociales y humanas debe ser visibilizada también. Si bien se reconoce teóricamente que los resultados de las disciplinas sociales están atravesados por relaciones sociales, en términos de la práctica cotidiana, persisten las mismas asociaciones binarias en muchos sentidos sacralizadas y rutinizadas que se satisfacen en reactualizaciones infinitas. En este sentido, junto con Mónica Da Cunha (2015), creo que hay una "violencia epistémica" en el acto de la omisión y de la forma estereotipada en la que nos mantienen esas reproducciones. Un ejemplo de las "incomodidades" que mencionaba al comienzo lo viví personalmente en la presentación de un libro sobre mujeres que habíamos compilado con otras colegas, todas mujeres, uno de los presentadores concluyó su rápida introducción afirmando que algunos de los

hombres; de limitar su creatividad; o de privarles de amplias áreas del conocimiento social y de los descubrimientos culturales" (Rich 1996, p. 26).

Revista Zona Franca- Centro de estudios interdisciplinario sobre las mujeres (CEIM)- Maestría poder y sociedad desde la problemática de género (MG), Rosario, Argentina. ISSN, 2545-6504 http://zonafranca.unr.edu.ar/index.php/ZonaFrancal Numero 27 (2019). 
capítulos del libro se podrían incluir en el programa de una materia sólo si quedaba tiempo para ello, después de repasar los aportes centrales sobre el tema. Pocas veces viví de manera tan elocuente y pública la invalidación de la producción de un grupo de mujeres, y con ello de mi propia producción, y la deslegitimación de nuestro derecho a formar parte, incluso, de la nómina de un programa. Las Lilits y las Evas son ominosas y oprobiosas para el Edén.

\section{Las tablas de la ley: las normas del género}

En el ámbito del Derecho Internacional de los Derechos Humanos, la Argentina suscribió la Convención sobre la eliminación de todas las formas de discriminación contra la mujer ${ }^{\vee}$, me interesa destacar que esta herramienta jurídica, de máxima jerarquía legal en nuestro país, si bien no tiene un apartado específico sobre la producción de conocimiento, propone que se acorte la brecha educativa y laboral que se mantiene entre varones y mujeres. Esto implica también que incluso, cuando las mujeres evidencian más y mejores credenciales educativas no son valoradas de la misma forma que las de los varones aun cuando que en el nivel terciario/universitario ya no son los varones quienes predominan, habiéndose producido también la feminización de algunas carreras.

El avance de las mujeres en estos ámbitos y su organización, aportó a favor de la visibilización de los micro-machismos, así en espacios de producción de conocimiento, como son las universidades y el propio CONICET, se desarrollaron una serie de normativas específicas tales como los protocolos de violencia de género o protocolos de violencia laboral que incluyen apartados específicos sobre género. El protocolo de CONICET menciona que es discriminatoria cualquier actividad que se constituya para disminuir la capacidad laboral de una persona en razón de su género. Esto incluye cualquier cosa que se haga para degradar o eliminar progresivamente a la mujer del lugar que ocupa.

\footnotetext{
$\checkmark$ Paradójicamente, firmada por Argentina en 1979 en plena dictadura y que, ratificada en 1985,
} adquirió jerarquía constitucional con la reforma constitucional de 1994.

Revista Zona Franca- Centro de estudios interdisciplinario sobre las mujeres (CEIM)- Maestría poder y sociedad desde la problemática de género (MG), Rosario, Argentina. ISSN, 2545-6504 http://zonafranca.unr.edu.ar/index.php/ZonaFranca| Numero 27 (2019). 
Florencia Rovetto y Noelia Figueroa (2017) consignan que la imposibilidad de aceptar la violencia como parte constitutiva de la ciencia es una barrera simbólica central para desmontar y avanzar en la modificación de esa situación. Esto lo aplican a la violencia de género en el ámbito universitario. En este sentido, ese universo representacional debería exponer la invisibilización de la problemática de género en la construcción del objeto y método disciplinar, la omisión y negación de un lugar a las cientistas y la apropiación de los resultados de sus producciones sin consignarlas.

Por eso, cuando con motivo de las Jornadas de sociología de la UBA, en 2017, un grupo de colegas se preguntó por las "madres de la sociología" y cuántas sociólogas se incorporaban en los programas de las materias, evidenciaron la omisión y los patrones paternalistas de la disciplina así como la estrategia de los padres de las ciencias sociales y humanas que engendran herederos por onanismo, clonación o adopción, reproduciendo la pauta viril en futuras generaciones ${ }^{\mathrm{VI}}$.

En esta línea, también podríamos preguntarnos cuántos colegas incorporan los resultados de las investigaciones de mujeres y sobre mujeres u otras identidades de género. Por ejemplo, cuántos estudios sobre sindicalismo -una de las temáticas sociohistóricas de más larga tradición (masculina)— referencian los resultados vinculados a la organización de las mujeres o, en los estudios más actuales, cuántos incluyen menciones al cupo laboral trans. En el sindicalismo, las mujeres fueron históricamente desconocidas ya que con su participación proponían un doble desafío: el de su participación en el mundo del trabajo simbólicamente incompatible con los roles de procreación y cuidado- y el de su participación en la política -fundante de un pacto de caballeros, que se presenta como pacto social, que omitió a las mujeres y las recluyó, violentamente, a lo privado doméstico tomando la voz en su nombre los varones. En este sentido,

${ }^{\mathrm{VI}}$ El efecto de ese hallazgo comenzó a expandirse a otras carreras y universidades (Rocha 2017).

Revista Zona Franca- Centro de estudios interdisciplinario sobre las mujeres (CEIM)- Maestría poder y sociedad desde la problemática de género (MG), Rosario, Argentina. ISSN, 2545-6504 http://zonafranca.unr.edu.ar/index.php/ZonaFranca| Numero 27 (2019). 
también, las mujeres -como sujetos históricos- deben esperar que aún los cientistas sociales -mayoritariamente, varones - recuerden que su participación ha sido relevante en las luchas sociales y las investigadoras deberán esperar además que consideren oportuno discutir sus resultados.

Esta omisión de las mujeres en el campo de las ciencias se realiza en nombre de una supuesta generalidad que tienen todos los demás campos centrados en sujetos masculinos- que hace que hablar sobre género suponga una particularidad, singularidad, que choca contra una supuesta universalidad que, en realidad, nunca es tal. Es el caso del colega que no cita un trabajo sobre las mujeres en tal o cual partido porque es algo específico y él quiere hablar sólo sobre el partido; o el caso de la revista de historia que rechaza un artículo sobre historia de las mujeres porque le sugiere mandarlo a una revista de la especialidad; o una ponencia sobre estudios de género y mujeres en la universidad que envía su trabajo a una mesa en un congreso sobre estudios de universidad y ésta la deriva a la mesa sobre movimiento feminista porque considera que es más pertinente allí. Todos ejemplos sacados de la vida académica de este último año.

En este sentido, estas normas no escritas -contradictorias con las escritasterminan reforzándose con prácticas de sociabilidad. La cofradía de los científicos -en masculino- define pautas de sociabilidad propias que, retomando el esquema de Rita Segato, podríamos considerar que constituyen formas de violencia epistémica basadas no sólo en una omisión sino también en la organización de ciertas prácticas que se consolidan en dos ejes. Un eje horizontal, "formado por términos vinculados por relaciones de alianza o competición" en el que los varones construyen y replican sus masculinidades científicas; y un eje vertical, "caracterizado por vínculos de entrega o expropiación" de las mujeres, de manera que ellos, sin ser iguales, se conforman como tales respecto de las mujeres (Segato, 2003, p. 253). El dividendo patriarcal se asienta, como dice Connell, en una división del trabajo que capitaliza la sexualización (Connell 1997;

Revista Zona Franca- Centro de estudios interdisciplinario sobre las mujeres (CEIM)- Maestría poder y sociedad desde la problemática de género (MG), Rosario, Argentina. ISSN, 2545-6504 http://zonafranca.unr.edu.ar/index.php/ZonaFranca| Numero 27 (2019). 
p. 41). Las mujeres, además, reciben las pautas del sistema científico y cuando captan el sexismo, creen -ilusamente- poder modificarlas; o generalmente, se adaptan a ellas sin cuestionarlas. Así se institucionalizan ciertas prácticas sin que sean estrictamente adrede, deliberadas o premeditadas, pero cuyo efecto causa un daño concreto a una persona por su condición de género. Cuando al final de una reunión de investigación las Evas levantan las tazas y las lavan. Los Adanes, con sus masculinidades cis aceptables, se quedan conversando de los temas abordados en la reunión y agregan comentarios sobre cómo las Lilit se retiraron sin más. Tenemos un buen ejemplo de esos sutiles condicionantes de género y, lamentablemente, esta es una práctica que no por aparecer clásicamente en los relatos de las investigadoras, deja de producirse.

Entonces, si en el esquema de jerarquías normativas, la legislación argentina atenta a la CEDAW suscribe que no se puede discriminar en razón de su género en su lugar de trabajo; ello no se constata cuando además de la ley, hay normas no escritas - cuya potencia se impone por la práctica y se concreta en una forma específica de sexismo en el ámbito científico.

\section{La institucionalización (del patriarcado)}

Estas cuestiones nos llevan a la tercera dimensión bajo escrutinio, la institucionalización la cual, como diría Scott (1996, p. 36), responde al momento en el que esas normas se cristalizan en pautas que se transmiten como mecanismos estratégicos de reproducción, donde las formas de discriminación por razones de género se instalan.

Algunos datos pueden ser ilustrativos de cómo opera la cofradía masculina (Maffía, n.d.-a) y se institucionaliza en un así son las cosas. Tomo por caso las categorías de investigadoras e investigadores en CONICET -un organismo científico público de referencia, que se encuentra en un proceso de desguace de recursos, mercantilización de sus hallazgos y desacreditación académica bajo el

Revista Zona Franca- Centro de estudios interdisciplinario sobre las mujeres (CEIM)- Maestría poder y sociedad desde la problemática de género (MG), Rosario, Argentina. ISSN, 2545-6504 http://zonafranca.unr.edu.ar/index.php/ZonaFranca| Numero 27 (2019). 
gobierno de Mauricio Macri. La información permite observar que las categorías superiores (principal y superior) del sistema científico están representadas mayoritariamente por varones y que, entre 2006 y 2016, si bien se redujo la brecha entre varones y mujeres, la persistencia a la ponderación masculina subsiste. Ello, no obstante, aún cuando se evidencia que las bases (asistente y adjunto/a) tienen mayor participación de las mujeres -un cambio notable en el decenio que, no obstante, no ha sido ponderado en las investigaciones y que tiene que ver con los recorridos y exigencias profesionales de las mujeres. Ya en la categoría intermedia (independiente), la brecha empieza a evidenciarse. Podría pensarse en un recambio generacional en el que las diferencias de género inciden menos para las nuevas generaciones; sin embargo, la pesquisa de números no es suficiente para una afirmación y se requiere una indagación más detallada del sistema de evaluación y los requerimientos de promoción no sólo formales sino, fundamentalmente, los ad hoc que asumen las comisiones.

Cuadro 1. Distribución por categoría y sexo Carrera de Investigación CONICET

\begin{tabular}{|c|c|c|c|c|c|c|c|c|c|c|}
\hline & \multicolumn{2}{|c|}{ Asistente } & \multicolumn{2}{c|}{ Adjunto/a } & \multicolumn{2}{c|}{ Independiente } & \multicolumn{2}{c|}{ Principal } & \multicolumn{2}{c|}{ Superior } \\
\hline & $\mathrm{V}$ & $\mathrm{M}$ & $\mathrm{V}$ & $\mathrm{M}$ & $\mathrm{V}$ & $\mathrm{M}$ & $\mathrm{V}$ & $\mathrm{M}$ & $\mathrm{V}$ & $\mathrm{M}$ \\
\hline 2006 & 42,4 & 57,6 & 48,1 & 51,9 & 57 & 43 & 70,4 & 29,6 & 82,4 & 17,6 \\
\hline 2016 & 40,2 & 59,8 & 46,4 & 53,6 & 51,3 & 48,7 & 60,7 & 39,3 & 74,2 & 25,8 \\
\hline
\end{tabular}

Fuente: CONICET

Ahora bien, para no hacer una lectura mecanicista, es importante señalar que, además del dividendo patriarcal entre varones, el modo en que el sistema logra su eficacia reposa, también, no sólo en las mujeres que se "adaptan" al sistema sino que, en particular, hace base en las mujeres que reproducen esos modelos porque asumen que llegaron por sus méritos -los que sin duda deben tener-pero hacen notar algún derecho como trabajadoras, digamos, la doble jornada, entonces, se produce una mengua en su valoración. De modo que aunque muchas mujeres logren insertarse en el campo de la ciencia, el hecho de que otras no lo hagan o lo hagan de modo marginal tiene que ver no sólo con la

Revista Zona Franca- Centro de estudios interdisciplinario sobre las mujeres (CEIM)- Maestría poder y sociedad desde la problemática de género (MG), Rosario, Argentina. ISSN, 2545-6504 http://zonafranca.unr.edu.ar/index.php/ZonaFranca| Numero 27 (2019). 
manera en que se constituye el campo sino también con el hecho de que es un campo absolutamente androcéntrico por lo que la participación de las mujeres significa el sometimiento a una forma de violencia "sobre los hábitos en los que han sido entrenadas y una desvalorización de todas aquellas capacidades para las que se las ha preparado", el rol de esposas y madres que persiste como modelo hegemónico (Maffía y Rietti 2005; p. 3) ) $^{\mathrm{VII}}$ Las becarias doctorales y postdoctorales, por ejemplo, no tuvimos durante muchos años licencia por maternidad. Cuando la obtuvieron, por ejemplo, en CONICET, muchas veces no se la acreditaron en tanto se otorgaba una prórroga general a quienes apostaran a presentarse a carrera de investigación. Entonces, su licencia quedaba subsumida en la extensión general y, cuando la reclamaban, se les espetaba que no les correspondía. Al mismo tiempo, también, la cantidad de días que se otorgan por licencia por paternidad en el ámbito científico supone que las tareas de cuidado recaen sólo en las madres. Vale decir, las becarias son tratadas como las Lilit que traicionaron el sistema por no haberse percatado de que su maternidad era incompatible con la lógica del sistema científico, las Evas no investigan; los Adanes, con una paternidad apenas reconocida.

Entre las estrategias que operan para que esto suceda, algunas fueron ya conceptualizadas por Alda Facio Montejo y utilizadas por otras autoras para abordar distintas problemáticas. Una de ellos es el androcentrismo y sus dos formas extremas, la misoginia (repudio a lo femenino) y la ginopia (imposibilidad de ver lo femenino o invisibilización de la experiencia femenina) ${ }^{\mathrm{VIII}}$. En este caso, nos encontramos frente a la preponderancia del arquetipo viril

"un modelo históricamente atribuido a varones adultos de raza y clase dominantes, fraguado por quienes, para ubicarse y legitimarse en el

\footnotetext{
VII Ibídem, p. 3.

VIII Facio Montejo considera que el androcentrismo "Se da cuando un estudio, análisis o investigación se enfoca desde la perspectiva masculina únicamente presentando la experiencia masculina como central a la experiencia humana y por ende la única relevante haciéndose el estudio de la población femenina cuando se hace, únicamente en relación a las necesidades experiencias y/o preocupaciones del sexo dominante masculino" (Facio Montejo 1992).
}

Revista Zona Franca- Centro de estudios interdisciplinario sobre las mujeres (CEIM)- Maestría poder y sociedad desde la problemática de género (MG), Rosario, Argentina. ISSN, 2545-6504 http://zonafranca.unr.edu.ar/index.php/ZonaFrancal Numero 27 (2019). 
centro regulador de la vida social -en el centro hegemónico-, se definen a sí mismos positivamente a base de definir negativamente cuantas actitudes y actuaciones humanas no participan de esa voluntad de poder, de esa actividad que cabe considerar anti-humana en la medida en que trata de imponerse sobre otras y otros mujeres y hombres" (Moreno i Sardá 2007, p. 97).

Ese arquetipo viril impregna la escena no sólo en el orden simbólico sino también en el palpable y visible de su dominio en un programa, de la intertextualidad en el diálogo investigativo, de la centralidad como sujeto de la investigación, etc. Como señala Facio Montejo, "Existe un ejercicio muy simple para detectar si una teoría o un resultado de una investigación etc., ha caído en androcentrismo. Consiste en invertir la teoría haciéndola ginocéntrica" (Facio Montejo 1992, p. 53) y, al ser vista desde esa perspectiva, debe consignarse si la teoría es inaceptable, inviable o inaplicable. Por otro lado, también como extremos de un continuum, aparecen tanto la sobregeneralización (que universaliza los resultados de una investigación como válidos para ambos sexos y, en realidad, surgen de hurgar exclusivamente sobre la conducta masculina) y la sobreespecificación (que considera como propio de un sexo conductas compartidas) y una posición que se aleja de aquellas dos, la insensibilidad al género (la que ignora la variable sexo como relevante). Luego, Facio menciona el doble parámetro, vale decir, la valoración contraria de una misma conducta según se trate de una mujer o un varón y, en vinculación estrecha con ello, la idea de que hay un "deber ser" sexualizado que genera conductas propias e impropias con base en un dicotomismo sexual. Con ello, volvemos a tocar los aspectos simbólicos a los que ya nos referimos al abordar a Frances Olsen y el modo en que el pensamiento binario construye estereotipos. En conjunto, las mieles de la igualdad operan a modo de promesa: el paraíso de la ciencia se le ofrece a todas las personas, sólo que alguna no estarían en condiciones de disfrutarlos por sus condicionamientos intrínsecos, los cuales son impedimentos para los méritos necesarios. Entonces, la pauta de promoción y reconocimiento no registra los 
propios criterios excluyentes sino que se posiciona en una fantasía promisoria de méritos que, en realidad, no es tal (Fox Keller, 1991). En ese esquema, el reconocimiento se demora para mujeres y sujetos excéntricos en general porque no se esfuerzan lo suficiente y no porque el sistema adrede expulse. La idea de carrera abierta al talento es muy frecuente como modo de pensarse en el ámbito académico y reproduce estrategias de corte individual, muy bienvenidas en el ámbito científico, y que, además, se condicen bien con lógicas de poder masculinizadas. Esos mecanismos operan con aceitados resortes que perpetúan el patriarcado científico que, además, se convierte en una eficaz moralizador a través de la meritocracia y los estándares nunca cumplidos por algunas personas, límite supuestamente irreprochable de la objetividad aséptica de los rigurosos requerimientos institucionales.

\section{La socialización patriarcal}

El proceso de socialización patriarcal atribuye características contrapuestas a cada sexo (dicotomismo sexual) y las jerarquiza, considerándose superiores los que están del lado masculino (doble patrón) y se forman expectativas de conducta para cada sexo basadas en ese dualismo (deber ser) (Facio Montejo 1992).

Ello incide, sin duda, en el modo en que se desarrolla en el terreno biográfico, la concepción de sí que cada persona tiene y construye en relación con el contexto social en el que vive.

Según Diana Maffía y Sara Rietti, "la ciencia occidental (...) aunque dueña de grandes logros, se desarrolló en el seno de un proyecto sociopolítico y cultural de carácter patriarcal y no igualitario" (Maffía y Rietti 2005, p. 541). En ese plano, sin desconocer los aportes que se hicieron en nombre de la ciencia, también se registran elementos negativos que vician el campo desde su constitución. Así, según estas autoras,

Revista Zona Franca- Centro de estudios interdisciplinario sobre las mujeres (CEIM)- Maestría poder y sociedad desde la problemática de género (MG), Rosario, Argentina. ISSN, 2545-6504 http://zonafranca.unr.edu.ar/index.php/ZonaFrancal Numero 27 (2019). 
"La dificultad intrínseca de esa sociedad para aceptar al diferente -entre ellos a las mujeres- $y$ la necesidad de verdades y caminos absolutos, hizo que desconocieran y descalificaran abordajes e intereses diferentes a cualquier otra forma de acercarse al conocimiento. Subsiste entonces un perfil excluyente e injusto: aquel que hace que esta ciencia lleve inscriptos muchos de los rasgos que caracterizan a la voluntad de predominio y exclusión" (Maffía y Rietti 2005, p. 541).

A las mujeres, en conjunto, nos parece que tenemos que publicar el doble que nuestros colegas varones puesto que, si ellos pasan con la mitad, nosotras podemos quedar en el camino con el doble en un informe de evaluación. Debemos esforzarnos por escribir en autoría individual y también colectiva de un modo equilibrado para no ser criticadas por individualistas o por falta de autonomía en una evaluación de esas que cada dos años establecen los criterios que garantizan nuestra continuidad en el sistema. Dudamos si explicar que nuestra producción se redujo si fuimos madres en el período del informe y, lo más probable, es que, de sólo pensarlo, prefiramos alcanzar el standard a cualquier costo. En general, los principales y superiores que nos evalúan son personas que no consideran nuestra trayectoria particular y nos exigen más, precisamente, porque no somos varones exudando la masculinidad "correcta". Esa situación se funda en aquellas representaciones sobre que lo que hacemos ni es tan científico ni es trabajo y, por supuesto, no es tan bueno.

Las Evas saben que deben exigirse más para quedarse en el Edén porque ya no es el mismo a causa de las Lilit que lo abandonan no sin antes blasfemar sobre ellos o peor aún, lo erosionan desde adentro regocijándose de la burla de los mandatos, desafiando con sus títulos degenerados que incluyen libido, anos y regocijos inadmisibles en el mundo de la ciencia... Las Lilit que asumen formas femeninas ejerciendo placeres que sólo le están reservados a los varones o invirtiendo las bases biológicas que originan el mandato del deber ser socavan las bases desde los cimientos, feminizándose aquellos que socialmente han sido consignados como biológicamente varones.

Revista Zona Franca- Centro de estudios interdisciplinario sobre las mujeres (CEIM)- Maestría poder y sociedad desde la problemática de género (MG), Rosario, Argentina. ISSN, 2545-6504 http://zonafranca.unr.edu.ar/index.php/ZonaFrancal Numero 27 (2019). 
Un querido colega ha sufrido en carne propia el atrevimiento de su desafío epistemológico y su propia elección sexual. Me refiero a lo vivido por mi colega Facundo Saxe quien vivió ominosas burlas sobre su trabajo y sobre su persona de parte de Eduardo Feinman que intentaba desprestigiar el sistema de investigaciones a partir del cuestionamiento de un título que involucraba palabras como ano e invocaba el placer; y fundamentalmente, haciendo referencias a su condición sexual y a su asunción de formas femeninas. Esa intervención mediática desató una catarata de mails y mensajes amenazantes del ejército de trolls que en este país se dedican a operar siniestramente en las redes sociales. Si bien un grupo de colegas organizamos un desagravio, buena parte del sistema científico políticamente correcto para ofrecer su solidaridad, pensaba y así lo manifestaba sotto voce, qué narcisismo había en el científico para querer llamar la atención poniendo títulos tan desubicados que nos desprestigiaban y quitaban mérito al resto de quienes investigan con seriedad. También, si el binarismo te clasifica entre los Adanes y no adoptás el régimen de masculinidad heterosexista, la consecuencia en estos contextos es sufrir el oprobio. La academia tiene su selectividad de género incluso mucho antes de que lleguemos a los niveles de competitividad profesional. Ya formándonos sería difícil que una persona trans termine sus estudios y, más difícil aún, que logre acceder al sistema científico. No es imposible encontrar algún ejemplo, claro, pero no es sino excepcional.

\section{Hacia un nuevo ¿Qué(hacer)?}

Un debate, larvado en muchos sentidos, se presenta en relación con las consecuencias de las luchas feministas, su relación con el contexto político y académico.

Como ha señalado Dora Barrancos:

\footnotetext{
"Probablemente la renovación tópica proveniente de los feminismos ha sido el motor que más renovación trajo a nuestras disciplinas, poniéndose de manifiesto las poleas sinergiales de la acción política y la producción
}

Revista Zona Franca- Centro de estudios interdisciplinario sobre las mujeres (CEIM)- Maestría poder y sociedad desde la problemática de género (MG), Rosario, Argentina. ISSN, 2545-6504 http://zonafranca.unr.edu.ar/index.php/ZonaFranca| Numero 27 (2019). 
académica. He aquí lo que podría auscultarse como un enorme servicio a la causa de la conquista de los derechos de las mujeres con repercusiones en muy diferentes sociedades. Si nos adentramos en la sumatoria de derechos conquistados en nuestro país no puede dejar de evocarse el producido académico, el aporte del feminismo académico a los combates por aumentar la ciudadanía. Por otra parte, si se trata de auscultar el estatuto contributivo de nuestras ciencias, se desprende que la conmoción epistemológica apuntada ha permitido acompañar a la agencia por los "derechos humanos" desde una perspectiva de sujetos muchos más amplia, anclada en las diversidades sexo-genéricas, desautorizando la inopia o la negligencia. Si se reflexiona sobre la conquista de derechos personalísimos en los últimos años en nuestro medio se podrá apreciar la colaboración prestada por nuestros conocimientos" (2019, p. 19).

Para val flores, por otra parte, en relación concretamente a lo que son los llamados movimiento de la diversidad sexual -vinculados a algunas corrientes del feminismo-, consigna que este vínculo es absolutamente problemático y disolvente del potencial disruptivo:

"La retórica de la diversidad nos instala en una epistemología neoliberal y colonial, en la que la compasión, la tolerancia, el respeto, la simpatía, constituyen fórmulas medulares de su prédica victimizante y paternalista. De este modo, se pone a circular lo otro en el mercado de lo conocido. Se destituye su heterogeneidad, se disuelve el episodio inaudito como efecto, para finalmente citar a comparecer a los sujetos otros -lesbianas, gays, travestis, transexuales, trans, bisexuales, intersex- en la categoría "diversidad" y domesticar así su emergencia rebelde. Sometido lo otro a su reordenamiento funcional en las burocracias discursivas de la academia y el Estado, hacen progresar el conocimiento de lo nuevo en la exclusiva dirección de significaciones calculables y administrables, en lugar de abrirlo al riesgo de lo intempestivo" (flores 2013, p. 305).

En otra oportunidad, he presentado parejas reflexiones en torno a la relación con el Estado y aquí podrían considerarse en relación con la ciencia. En efecto, nos encontramos en el orden de las paradojas -como definió Scott (2012)- y

Revista Zona Franca- Centro de estudios interdisciplinario sobre las mujeres (CEIM)- Maestría poder y sociedad desde la problemática de género (MG), Rosario, Argentina. ISSN, 2545-6504 http://zonafranca.unr.edu.ar/index.php/ZonaFrancal Numero 27 (2019). 
pugnamos por cambios en un sistema que nos fagocita y desvirtúa muchas veces nuestras demandas y, a la vez, no podemos gestar -ni ha sido propuesta - una alternativa fuera del sistema. Sin embargo, transitar ese sistema nos compele a no aceptar el statu quo, aún a sabiendas de cómo puede terminar todo siendo aceptable, correcto, manejable (Valobra 2015).

Ahora bien, me interesa cerrar estas ideas con algunas consideraciones. En primer lugar, qué hacer ante un panorama tan desolador. Poder discernir que muchas colegas no son sensibles a los problemas de las mujeres en el sistema científico por el solo hecho de ser mujeres y que muchos colegas no reproducen esos cánones y que tienen una sensibilidad a la temática de género. Tampoco quiero ser la plañidera de los derechos que nos han cercenado porque creo que esos derechos los hemos conseguido y, asimismo, me incomoda pensar que permanecer en el sistema científico con todo esto es convertirme en una Eva que acepta su destino y que salirme del sistema como Lilit es la solución. Son, también, situaciones de respuesta individual que también me incomodan.

Ello me invita a plantear, para cerrar, la cuestión de la importancia de pensar estrategias más sensibles y dialógicas. Diana Maffía y Sara Rietti apuntan a que es necesario discutir las normas del campo científico que "se aceptan como única alternativa" (Maffía y Rietti 2005, p. 541). De ese modo, proponen dislocar el modo de producción científico, sus regulaciones, estilo, jerarquía y objetivos, lo cual no se resuelve sólo con sumar mujeres, también es necesario ampliar la participación en todos los niveles, aunque desnaturalizando la valorización de la ciencia y la desvalorización de las mujeres dentro del propio campo. Existen numerosos ejemplos en la historia de la ciencia en los cuales se desconoce el valor cognitivo de las mujeres o las razones de sus elecciones a la hora de abordar o desechar ciertos proyectos vinculados a las ciencias duras o humanas. Indagar sobre ello puede arrojarnos información útil y sorprendente incluso para propulsar el campo

Revista Zona Franca- Centro de estudios interdisciplinario sobre las mujeres (CEIM)- Maestría poder y sociedad desde la problemática de género (MG), Rosario, Argentina. ISSN, 2545-6504 http://zonafranca.unr.edu.ar/index.php/ZonaFranca| Numero 27 (2019). 
del conocimiento científico (Maffía y Rietti 2005, p. 541) ${ }^{\mathrm{IX}}$. En este sentido, la pregunta por la epistemología feminista sigue siendo una apuesta política y académica. En ese sentido, Sandra Harding (1998) y Evelyn Fox Keller (1991) desarrollaron una de las premisas básicas de una epistemología feminista que se vincula con lo que se denomina la reflexividad, es decir, la particular situación que debemos resolver como sujetos que integran el mundo que estudian y es la subjetividad una parte determinante de la delimitación y construcción de un objetivo de estudio (Burawoy, 2018). Ese método feminista -si salvamos las distintas definiciones que supone el concepto (Harding, 1998)- debería, rechazar los dualismos (Fox Keller, 1991); reconocer el modo en que distintos atravesamientos, puntualmente, la de género incide en la construcción del conocimiento (Fox Keller, 1991) tanto en el modo en que esa cuestión incide en el acercamiento al tema, en las estrategias que se diseñan, el modo en que la subjetividad incide en la delimitación del tema y problema así como en la construcción de los datos de investigación. Ello, básicamente, implica, según Fox Keller (1991), desmitificar la creencia de una ciencia impersonal. Asimismo, supone reconocer los aportes de las mujeres a la ciencia y también los que ha producido la ciencia construida desde lo masculino. Ello se complementa con lo expresado por Harding (1998) que no sólo reclama el ejercicio de la reflexividad sino, también, colocan una ciencia a favor de las mujeres en el sentido de recuperar y valorar sus experiencias y, al mismo tiempo, en poner a la investigadora en el mismo plano crítico que el objeto explícito de estudio (Harding, 1998, p. 24). Desde esta perspectiva, esas estrategias permiten modificar no sólo el objeto de estudio sino, también, cambiar el modo en que se encamina el proceso de investigación $\mathrm{y}$, asimismo, del que se obtienen resultados de investigación.

\footnotetext{
IX Idem. El caso de Evelyn Fox Keller es emblemático. Fue su crítica a la noción de jerarquía lo que la llevó en los '60 a uno de los descubrimientos más importantes de la biología y los sistemas colectivos emergentes, aunque tardó muchísimo en reconocerse su aporte liminar y la aplicación a otros campos. Una síntesis de esos aportes en Johnson 2003.
}

Revista Zona Franca- Centro de estudios interdisciplinario sobre las mujeres (CEIM)- Maestría poder y sociedad desde la problemática de género (MG), Rosario, Argentina. ISSN, 2545-6504 http://zonafranca.unr.edu.ar/index.php/ZonaFranca| Numero 27 (2019). 
Un segundo aspecto, además del que expuse más arriba, es el que se vincula con la pedagogía feminista, la docencia con perspectiva de género que suponga también un desafío político. Volver a este campo no es "feminizar" el problema de la investigación con sus subalternidades asociadas en el sistema imperante. Muy por el contrario, es comprender que es un aspecto solidario de la conformación de una crítica feminista. No hay ninguna epistemología feminista si no se construye con una pedagogía tal. Es como prenteder que la sororidad no integre el vocabulario de las feministas. Como dice Claudia Korol (2007), la pedagogía feminista que ella pregonaba se nutrió de la de Paulo Freire y, aunque no tenía una perspectiva de género ínsita, se apropió de ella por todo lo que sí le brindaba para desplegar la pedagogía feminista. Como maestra que soy, también abracé la obra de Freire y si bien rápidamente me di cuenta de la gran contradicción de enseñar en lo que Althusser (1988) llamó los "aparatos ideológicos del estado" y esperar, a la vez, una revolución; ya no pude ya dejar de ejercer la docencia con una expectativa transformadora, convencida de que, en alguna medida, esa experiencia podía sedimentarse en muchas otras que contribuyeran en ese camino. Si bien no creo que se pueda enseñar a quien no quiere aprender la pedagogía nos permite un doble ejercicio: por un lado, enseñar, por el otro aprender. El fin es tener una sensibilidad y práctica reflexivas sobre la equidad de géneros que nos permitan vehiculizar una transformación.

La pedagogía feminista nos exige, también, una gran imaginación y energía porque, en efecto, tenemos que desmontarnos de esos preceptos socializadores y, a su vez, exponerlos a otras personas. En primer lugar, el ejercicio de la visibilidad todavía es necesario -aún cuando al hacerlo es altamente probable que sólo queden expuestas un número muy reducido de mujeres que, por distintas razones, tuvieron la posibilidad de quedarse en el campo y, tal vez destacarse, frente a un conjunto enorme que no logró dicha inserción o, desde ya, frente a un conjunto aún más amplio de otras identidades de género para quienes LA CIENCIA, con mayúsculas, les está vedada a priori porque, en gran medida, la

Revista Zona Franca- Centro de estudios interdisciplinario sobre las mujeres (CEIM)- Maestría poder y sociedad desde la problemática de género (MG), Rosario, Argentina. ISSN, 2545-6504 http://zonafranca.unr.edu.ar/index.php/ZonaFrancal Numero 27 (2019). 
educación es un privilegio para quienes mayoritariamente siguen la pauta heterosexual.

Además, creo que debemos también insistir en una reflexión más cabal y conmovedora de las interpretaciones existentes, porque estamos en un momento de mera declamación de que la incorporación de sujetos generizados como sujetos históricos cambia las interpretaciones y apenas si formulamos debates y discusiones con quienes abordan ese tema desde otras perspectivas. Si bien considero que el ejercicio de la visibilización aún es necesario, no es suficiente. Son muy importantes los espacios de género para tener nuestros ámbitos de discusión que nos permitan encontrar un vocabulario propio, maneras de transmitir, modos de conmover los marcos teóricos y metodológicos (punto que ha sido, a mi modo de ver, el que menos se ha logrado modificar en términos de la perspectiva de género y que ha privilegiado las líneas cualitativas), pero creo también que debemos dar debate en esas mesas de congresos que creen que hacemos cosas particulares y de mera visibilización. No sólo poner de manifiesto que "los demás no nos entienden", también necesitamos poder explicarnos mejor y colocar en nosotros la incapacidad de expresarnos de manera comprensible.

\section{Volviendo a mirarnos el ombligo}

Más de una vez he escuchado relatos de mis compañeras del ámbito académico que tienen una base común. En una reunión, especialmente si son las únicas mujeres, pueden ser objeto de miradas masculinas que las observan sin comprender por qué las exalta tanto que no hayan incluido a una mujer en el comité académico de tal o cual reunión o por qué se molestan si no citan sus trabajos que, después de todos, son "particulares". Y estos relatos no me son ajenos, también los he vivido en primera persona y, de algún modo, este texto es un intento de "destilar teoría de los textos de nuestras vidas" (Flores 2013, p. 24). Las Lilits que dejan el Edén -o al menos, algunos de sus espacios- o las Evas que se quedan en él -a veces sin darse cuenta de su situación- son visualizadas

Revista Zona Franca- Centro de estudios interdisciplinario sobre las mujeres (CEIM)- Maestría poder y sociedad desde la problemática de género (MG), Rosario, Argentina. ISSN, 2545-6504 http://zonafranca.unr.edu.ar/index.php/ZonaFranca| Numero 27 (2019). 
como "conflictivas" la una por la confrontación; la otra, por su sumisión. Alternativamente, podemos en una sola persona ser las Lilits y las Evas porque esta situación parte de una mirada relacional. Por lo tanto, entiendo que, si hablo de mujeres, no lo estoy haciendo en un sentido esencial, sino social relacional y que no adscribo lo femenino a la genitalidad convertida en definitoria, aun cuando así se construye socialmente. Finalmente, lo que todos los relatos de mis colegas tienen en común es a ese grupo de científicos, algunos de ellos que pueden incluso ser cercanos compañeros y hasta amigos, unidos por esa gran incomprensión sobre nuestra irracionalidad o nuestra falta de paciencia para explicarles, una vez más, que eso que están haciendo también es sexismo, aunque sean los más "progres" Adanes de la academia, siempre que estén apegados a la masculinidad hegemónica.

La definición de género y la mirada relacional es constitutiva y sociohistórica y consideran a los sujetos no como un ex ante, sino como un constructo singular de las relaciones sociales en un momento histórico determinado y oblitera concepciones binarias y biologicistas. Además, nos obliga a un ejercicio de introspección permanente. En efecto, y aquí voy a cerrar con lo que fue la experiencia de escribir una respuesta a Tim Hunt para Página 12. El diario nos convocó a 12 mujeres del ámbito científico para contestar las desafortunadas expresiones del premio Nobel británico quien había sostenido, entre otras cosas, "Déjenme que les cuente cuál es mi problema con las mujeres", empezó Sir Tim Hunt -quien recibió el prestigioso premio en 2001- durante una intervención en una conferencia reciente.

"Tres cosas ocurren cuando uno comparte el laboratorio con ellas: se enamoran de uno, uno se enamora de ellas y cuando se las critica, ellas lloran", y aunque luego se disculpó e incluso renunció a su cargo universitario, las repercusiones fueron notables.

Revista Zona Franca- Centro de estudios interdisciplinario sobre las mujeres (CEIM)- Maestría poder y sociedad desde la problemática de género (MG), Rosario, Argentina. ISSN, 2545-6504 http://zonafranca.unr.edu.ar/index.php/ZonaFrancal Numero 27 (2019). 
En la respuesta en Página 12, para la que elegí el sugerente título de connotaciones bíblicas y onanísticas, como me observó una querida colega, "La paja en el ojo ajeno"; sostuve que la idea que expone Hunt sobre enamorarse de colegas y luego no soportar que se critique su trabajo y, más aún, no poder avanzar en la ciencia y proponer espacios segregados por género, supone una construcción de conocimiento jerarquizada, de crítica personal y ególatra, aderezada con una incontinencia heterosexual compulsiva. Supone un modelo de objetividad ilusorio, ya que borra al sujeto. Esto nos coloca dramáticamente frente a lo omitido, incluso en las respuestas a esta violencia: cuerpo, emociones y subjetividades forman parte de nuestro conocimiento. Creo que no es negándolo que propondremos nuevos parámetros científicos ni es, lógicamente, reduciéndolo a una mirada misógina que cambiaremos paradigmas tan arraigados (Valobra 2015).

Efectivamente, podemos distraernos -como cualquiera - al trabajar con otra persona, cometer un error si atravesamos un momento emocionalmente difícil y ver bloqueadas nuestras intelecciones por nuestra subjetividad. Sin embargo, es todo eso lo que también potencia nuestras comprensiones en diálogo con colegas; es en el momento en que nuestras emociones y convicciones se ponen en juego cuando se forja la voluntad para investigar; es, finalmente, nuestra propia subjetividad la que puede ampliar lecturas sobre un fenómeno. Reconocer esto significa revisar cómo construimos un saber y cómo se ponen en juego lo racional, lo emocional, lo corporal, lo etario, lo genérico, lo clasista, lo étnico y tantas otras dimensiones, porque el conocimiento científico en cualquier disciplina se equivoca por las mismas razones por las que acierta. En esa tensión me parece interesante pensarnos.

Hunt es el emergente de un sistema social sustentado en la dominación de los varones sobre las mujeres, de una jerarquía instituida por un modelo de género y un esquema de cientificidad masculinizado en sus métodos, indicadores. Es un sistema violento sobre el cuerpo, la mente y las emociones de las mujeres y sobre

Revista Zona Franca- Centro de estudios interdisciplinario sobre las mujeres (CEIM)- Maestría poder y sociedad desde la problemática de género (MG), Rosario, Argentina. ISSN, 2545-6504 http://zonafranca.unr.edu.ar/index.php/ZonaFrancal Numero 27 (2019). 
cualquier persona que no se apega a esos estereotipos, lo que se considera una feminización excluyente. No deja de ser violento cuando una mujer aprehende esos valores y los reproduce, llegando incluso a autoimpugnarse. Reconocer esta situación puede ser un primer paso para cambiarla. $Y$ las feministas no estamos exentas de reproducirlas. En conjunto, este último aspecto que considero relevante requiere no sólo de un trabajo de implicación personal, sino también colectiva, de preguntarnos cuánto de Hunt tenemos. Particularizarlo y preguntarme cuánto de Hunt hay en mí y de qué modo puedo modificarlo, si es que puedo, en los lazos sociales que tejo cotidianamente. Las mujeres, también en la ciencia, hemos encontrado en los espacios colectivos una estrategia de gran potencia para dar cauce a esta tarea deconstructiva.

\section{Bibliografía}

ALTHUSER, Louis (1988). Ideología y aparatos ideológicos del Estado. Freud y Lacan, Nueva Visión, Buenos Aires.

BACH, Ana María (2018). "Epistemologías actuales: los saberes de las gentes indígenas", en Descentrada, 2(2) SE-Dossier Epistemologías críticas feministas.

https://www.descentrada.fahce.unlp.edu.ar/article/view/DESe051

BARRANCOS, Dora (2019). “¿Para qué sirven las Humanidades?”, en Arán, Pampa y Casarín, Marcelo (coord.). Ciencias sociales: balance y perspectivas desde América Latina, Córdoba, Centro de Estudios Avanzados.

BOURDIEU, Pierre (2000). La dominación masculina, Barcelona, Anagrama.

CAMPAGNOLI, Mabel (2018). "Epistemologías críticas feministas. Aproximaciones actuales", en Descentrada, 2(2) e047, https://www.descentrada.fahce.unlp.edu.ar/article/view/DES047

CICCIA, Lucía (2018). "La dicotomía de los sexos puesta en jaque desde una perspectiva cerebral", en Descentrada, 2(2) e052, https://www.descentrada.fahce.un/p.edu.ar/article/view/DESe052

Revista Zona Franca- Centro de estudios interdisciplinario sobre las mujeres (CEIM)- Maestría poder y sociedad desde la problemática de género (MG), Rosario, Argentina. ISSN, 2545-6504 http://zonafranca.unr.edu.ar/index.php/ZonaFranca| Numero 27 (2019). 
CONNELL, Raewyn [Robert]. (1997). "La organización social de la masculinidad", en Valdés, Teresa y Olavarría, José (Ed.). Masculinidad/es: poder y crisis, Santiago de Chile, ISIS-FLACSO, Ediciones de las Mujeres № 24, (77-89). http://joseolavarria.cl/wp-content/uploads/downloads/2014/08/Masculinidad-podery-crisis-Valdes-y-Olavarria.pdf

DA CUNHA, Monica (2015). "El currículum como Speculum", en Ana M. Bach (Ed.), Para una didáctica con perspectiva de género, Buenos Aires, Miño y Dávila Editores (153-185).

FACIO MONTEJO, Alda (1992). Cuando el género suena, cambios trae,San José de Costa Rica, ILANUD.

FALQUET, Jules (2017). "La combinatoria straight. Raza, clase, sexo y economía política: análisis feministas materialistas y decoloniales", en Descentrada, http://www.descentrada.fahce.unlp.edu.ar/article/view/DESe005/7993

FLORES, valeria (2013). interrupciones. ensayos de poética activista escritura, política, pedagogía. Neuquén: Editora La Mondonga Dark. http://escritoshereticos.blogspot.com/2014/11/interruqciones-libro-paradescargar.html

FRASER, Nancy (1993). "Reconsiderando la esfera pública: una contribución a la crítica de la democracia existente", Debate Feminista, marzo, Disponible en http://www.debatefeminista.cieg.unam.mx/wpcontent/uploads/2016/03/articulos/00 7 02.pdf, 23-58.

FOX KELLER, Evelyn (1991). Reflexiones sobre género y ciencia, Valencia, Alfons El Magnànim.

JOHNSON, S. (2003). "Introducción", en Sistemas emergentes - O qué tienen en común hormigas, neuronas, ciudades y software, Buenos Aires, Fondo de Cultura Económica.

KOROL, Claudia (comp.). (2007). Hacia una pedagogía feminista Géneros y educación popular, Buenos Aires, El Colectivo América Libre. 
https://libros.metabiblioteca.org/bitstream/001/434/1/Hacia

una

pedagogía feminista.pdf

LEWONTIN, Richard; ROSE, Steven y KAMIN, Leon (1987). No está en los genes. Racismo, genética e ideología, Barcelona, Crítica.

MAFFíA, Diana (n.d.-a). “¿Es sexista la ciencia? (Cómo probar la discriminación en las comunidades científicas con las mismas herramientas de la ciencia) (mimeo). http://dianamaffia.com.ar/archivos/Es-sexista-la-ciencia.pdf

MAFFÍA, Diana (n.d.-b). Contra las dicotomías: feminismo y epistemología crítica, Buenos Aires, Seminario de epistemología feminista-Facultad de Filosofía y Letras-Universidad de Buenos Aires.

MAFFÍA, Diana (2003). Sexualidades migrantes género y transgénero. Buenos Aires, Feminaria

Editora. http://dianamaffia.com.ar/archivos/sexualidadesmigrantesdm.pdf

MAFFÍA, Diana y, \& RIETTI, Sara (2005). "Género, ciencia y ciudadanía”, en Arbor: Ciencia, Pensamiento y Cultura, (716), 539-544. http://arbor.revistas.csic.es/index.php/arbor/article/view/411

OLSEN, Frances (1990). "El sexo del derecho", en Kairys, David (Ed.). The Politics of Law, New York, Pantheon, (452-467).

PATEMAN, Carole (1995). El contrato sexual, Barcelona-México, AnthroposUniversidad Autónoma Metropolitana.

PÉREZ, Pablo Ernesto (2008). La inserción ocupacional de los jóvenes en un contexto de desempleo masivo. El caso argentino entre 1995 y 2003, Buenos Aires, Miño y Dávila.

$\mathrm{RICH}$, Adrienne (1996). "Lesbiana, Heterosexualidad obligatoria y existencia", en DUODA Revista d'Estudis Feministes, (10), 15-45.

ROCHA, Milagros (2017). "La historia del género y el género en historia. Apuntes preliminares dentro del profesorado en Historia de la Universidad Nacional de La Plata", en Clío y Asociados, (25), 86-97. http://www.memoria.fahce.unlp.edu.ar/art revistas/pr.8627/pr.8627.pdf

Revista Zona Franca- Centro de estudios interdisciplinario sobre las mujeres (CEIM)- Maestría poder y sociedad desde la problemática de género (MG), Rosario, Argentina. ISSN, 2545-6504 http://zonafranca.unr.edu.ar/index.php/ZonaFranca| Numero 27 (2019). 
ROVETTO, Florencia y FIGUEROA, Noelia (2017). "'Que la universidad se pinte de feminismos' para enfrentar las violencias sexistas", en Descentrada, 1(2) https://www.descentrada.fahce.unlp.edu.ar/article/view/DESe026

SCOTT, Joan W. (1996). "El género: una categoría útil para el análisis histórico", en Dubois, Cecilia y Cangiano, Lindsay (comp.). De Mujer a género. Teoría, interpretación y práctica feminista en las Ciencias Sociales, Buenos Aires, CEAL.

SCOTT, Joan W. (2012). Las mujeres y los derechos del hombre: Feminismo y sufragio en Francia, 1789-1944, Buenos Aires, Siglo Veintiuno Editores.

SEGATO, Rita (2003). Las estructuras elementales de la violencia, Bernal, Editorial de la UNQ.

VALOBRA, Adriana M. (2015). "El Estado y las mujeres, concepciones en clave feminista", en Estudios Sociales Del Estado, I(2), 32-57. http://www.estudiossocialesdelestado.org/index.php/ese/article/view/44

WAYAR, Marlene (2018). Travesti/Una teoría lo suficientemente buena. Buenos Aires, Editorial Muchas Nueces.

ZTARDUST, Morgan (2013). "Aquí se escribe (y se corta) con la lengua”, en Interrucqciones, ensayos de poética activista escritura, política, pedagogía. Neuquén: Editora La Mondonga

Dark. http://escritoshereticos.blogspot.com/2014/11/interruqciones-libroparadescargar.html 